\title{
Reflets
}

Revue ontaroise d'intervention sociale et communautaire

\section{Fiches atouts! Trousse de formation sur la violence conjugale et l'agression sexuelle contre les femmes}

\section{Marie-Luce Garceau}

Volume 6, numéro 1, printemps 2000

Approches d'intervention : définir et renouveler nos pratiques

URI : https://id.erudit.org/iderudit/026305ar

DOI : https://doi.org/10.7202/026305ar

Aller au sommaire du numéro

Éditeur(s)

Reflets : Revue ontaroise d'intervention sociale et communautaire

ISSN

1203-4576 (imprimé)

1712-8498 (numérique)

Découvrir la revue

Citer cet article

Garceau, M.-L. (2000). Fiches atouts! Trousse de formation sur la violence conjugale et l'agression sexuelle contre les femmes. Reflets, 6(1), 216-219. https://doi.org/10.7202/026305ar

Tous droits réservés (C) Reflets : Revue ontaroise d'intervention sociale et communautaire, 2000
Ce document est protégé par la loi sur le droit d'auteur. L'utilisation des services d'Érudit (y compris la reproduction) est assujettie à sa politique d'utilisation que vous pouvez consulter en ligne.

https://apropos.erudit.org/fr/usagers/politique-dutilisation/ 


\title{
Fiches atouts! Trousse de formation sur la violence conjugale et l'agression sexuelle contre les femmes
}

\author{
Marie-Luce Garceau, \\ École de service social, Université Laurentienne
}

Dans la majorité des organismes sociaux et communautaires qui offrent de la formation à des professionnels ou à des bénévoles, on insiste depuis de nombreuses années sur le besoin d'avoir des outils de travail qui soient adaptés à la réalité de l'Ontario français. On entend souvent des commentaires comme «on ne peut pas tout traduire» ou encore, «cette formation est intéressante, mais il faudrait qu'elle réponde mieux aux besoins». Devant cette denrée rare, le Centre Victoria pour femmes de Sudbury a produit une trousse de formation pour les bénévoles œuvrant auprès des femmes francophones victimes d'agression à caractère sexuel et de violence conjugale, qui a pour nom : Fiches atouts! ${ }^{1}$.

Fiches atouts! est une trousse destinée principalement à la formation des bénévoles qui œuvrent à la ligne de crise des centres d'aide francophones de l'Ontario. Toutefois, celle-ci ne s'y limite pas, car elle peut être utilisée par les intervenantes et les femmes qui travaillent directement ou indirectement auprès des victimes d'agression à caractère sexuel ou de violence conjugale. Elle peut aussi servir à faire de la prévention et de la sensibilisation dans ces deux domaines. Dans ce dernier cas, certaines fiches peuvent être très utiles aux enseignantes ou aux conseillères des niveaux secondaires, collégiaux ou universitaires. 
Les thèmes présentés dans Fiches atouts! ont été choisis afin d'offrir le plus d'informations possible et de permettre aux intervenantes, aux bénévoles ou à toutes les personnes intéressées de bien connaitre les problématiques de la violence et de l'agression et d'intervenir adéquatement auprès des femmes, quelles que soient les situations auxquelles elles sont confrontées.

Les critères qui ont guidé la rédaction des Fiches atouts! sont les suivants : l'accessibilité du langage, des informations précises sur chacun des thèmes et un format pratique incluant des exercices d'animation et des suggestions sur les ressources disponibles selon les thèmes abordés.

\section{Comment utiliser la trousse Fiches atouts!}

La trousse d'animation et de formation Fiches atouts! peut être utilisée en tout ou en parties selon les besoins des utilisatrices. Elle comprend vingt et une (21) fiches regroupées en cinq parties. La première offre des informations de base portant sur le phénomène de la violence faite aux femmes, l'oppression des femmes, l'intervention féministe, l'historique des centres d'aide et le rôle des bénévoles.

La seconde partie aborde la question des agressions à caractère sexuel, en présentant les différentes formes d'agression. Elle traite de l'abus durant l'enfance et des autres formes d'abus, des procédures médicales et judiciaires et, finalement, du harcèlement sexuel.

La troisième partie lève le voile sur la violence dans les relations amoureuses. Il est donc question de violence conjugale, de violence dans les fréquentations et dans les relations lesbiennes. On met aussi l'emphase sur la violence vécue par les femmes immigrantes. En dernier lieu, on aborde les procédures médicales et judiciaires qui sont liées à la violence conjugale et à celle dans les fréquentations.

Dans la quatrième partie, il est question des modèles d'intervention utilisés auprès des femmes agressées ou violentées. 
Toujours en lien avec l'intervention féministe, on développe les modèles d'intervention en situation de crise, de groupe de soutien, de dynamique de groupe et d'intervention auprès des personnes suicidaires. Afin de compléter ce portrait, on montre comment il est possible d'enrayer les mécanismes de dépendance adoptés par les victimes.

Enfin, la cinquième et dernière partie des Fiches Atouts!, présente quelques outils de changement social. Ces outils peuvent être utilisés par celles qui souhaitent sensibiliser leurs milieux à l'agression à caractère sexuel et à la violence faite aux femmes et ainsi favoriser des changements tant au niveau de leur communauté qu'au niveau social.

Chaque fiche est conçue selon un format unique. Vous y trouvez :

- une définition, des statistiques et de nombreuses informations sur le thème;

- des suggestions de ressources et de lectures complémentaires;

- une proposition de déroulement des rencontres;

- des annexes comportant des exercices d'animation, des notes ou des scénarios, etc., qui peuvent être photocopiées et distribuées et, enfin

- quelques fiches sont accompagnées d'outils d'intervention pour faciliter la tâche des intervenantes.

Nous ne prétendons pas que Fiches atouts! présente le fin mot de l'histoire de ces réalités complexes. Plutôt, nous considérons que cet outil de formation est perfectible. C'est pourquoi nous souhaitons que les intervenantes qui l'utiliseront, fassent part de leurs commentaires et qu'elles se sentent tout à fait libre d'y ajouter d'autres informations pertinentes, des exercices d'animation, des ressources, etc.

Pour se procurer ou avoir de l'information sur les Fiches atouts!, veuillez vous adresser au : Centre Victoria pour femmes, C.P. 308, Sudbury, Ontario, P3E 4P2. Téléphone : (705) 6702517. Télécopieur : (705) 670-2645. Courrier électronique : victoria@isys.ca 


\section{Note}

1. Ce projet a été marrainé, conçu et produit par le CentreVictoria pour femmes de Sudbury. Il a également bénéficié de l'appui et de la participation d'intervenantes des Centres d'aide offrant des services aux femmes d'expression française en Ontario et de plusieurs femmes de la communauté. Nous tenons particulièrement à remercier Condition féminine du Canada pour son appui financier. 